\title{
OPERATION-ORIENTED STUDIES ON WEAR PROPERTIES OF SURFACE-HARDENED ALLOY CAST STEELS USED IN MINING IN THE CONDITIONS OF THE COMBINED ACTION OF DYNAMIC FORCES AND AN ABRASIVE MATERIAL
}

\begin{abstract}
This paper presents the results of wear tests of shot-peened and not shot-peened cast steels used in the mining machinery industry, in particular in the construction of chain drums for armoured face conveyors. Wear tests were carried out in the conditions corresponding to the real operating conditions of armoured face conveyors during drifting work in rocks such as sandstone. The operating factors subjected to the analyses included the presence of quartz abrasive and the impact of external dynamic forces. On the basis of the wear tests as well as the microhardness and microstructure examinations performed, it has been found that the action of an additional dynamic force has a synergistic impact on the process of abrasive wear in loose quartz abrasive. It has been further found that the value of abrasive wear of chain wheels operated in the conditions of a combined action of abrasive and a dynamic force depends on whether the area of mating of wheels with the chain was shot-peened or not before the wear tests - an increase in the abrasive wear was observed for the wheels made of cast steel subjected to shot peening in the area of mating with the chain. Lower resistance to abrasive wear of the cast steels subjected to shot peening before the wear tests could result from the formation of cracks in the surface layer caused by the action of shot.

Keywords: steel cast, dynamic force, synergism, wear, shot-peening
\end{abstract}

\section{Introduction}

At the stage of designing the elements essential for providing the required functionalities of machines and equipment operating in harsh environmental conditions, the attention should be paid to such a selection of materials so that the possibility of operation in conditions of the real impact of operating factors is ensured [1]. That's because during the operation of machines and equipment, there takes place a combined action of factors inducing the processes of destruction of individual elements of the machines. In many cases the action of these factors is accompanied by an increase in the intensity caused by a mutual synergistic [2] impact of the destruction processes.

In this study, a hypothesis was accepted that the combined action of quartz abrasive and external dynamic forces should increase the wear of surfaces of the teeth of chain wheels made of cast steel. Such a relationship was identified in [3] for the chain wheels made of austempered ductile iron subjected to wear tests in the presence of quartz abrasive and an additional dynamic load. The expected combined impact of both factors intensifying destructive processes should cause an effect of synergy that can be presented in the form of the following relationship:

$$
V_{T}=V_{A B R}+\Delta V_{D Y N}
$$

where:

$V_{T}-$ total wear,

$V_{A B R}$ - abrasive wear,

$\triangle V_{D Y N}$ - synergistic components.

After a simple transformation, the synergistic component $\Delta V_{D Y N}$ associated with the action of dynamic forces can be determined using the following formula:

$$
\triangle V_{D Y N}=V_{T}-V_{A B R}
$$

The main aim of this study was to demonstrate the existence of a synergistic effect accompanying the operation of chain drums made of surface-hardened alloy cast steel used as parts of mining machinery. According to formula (2), the determination of the synergistic component $\Delta V_{D Y N}$, which is a parameter characterizing the synergy of destructive processes, required carrying out two series of wear tests - one in the conditions of abrasive wear and another one in the conditions of combined impact of an abrasive material and an external dynamic force. Another important aim of this study was to analyse the impact of applying a surface dynamic treatment (shot peening) before the wear tests. In [4-9], a positive influence of shot peening on the performance characteristics of the toothed elements has been observed - in particular on the fatigue strength, increase in the hardness of the surface, and introduction of beneficial

SILESIAN UNIVERSITY OF TECHNOLOGY, FACULTY OF MINING AND GEOLOGY, 2 AKADEMICKA STR., 44-100 GLIWICE, POLAND

Corresponding author: Andrzej.N.Wieczorek@polsl.pl 
compressive residual stresses to the surface layer. However, the preliminary studies [10] concerning the impact of shot peening on the abrasive wear of the area of mating between the chain wheels and the chain did not confirm such a beneficial impact of this process.

\section{Experimental Details}

The tests of wear properties of alloy cast steels were carried out on an especially designed test rig that allows reproducing the real operating conditions of chain wheels (a detailed description was given in $[11,12])$. During the studies, real chain wheels which are components of drive units of transport conveyors were tested. The adopted conditions of the tests corresponded to the real operating conditions of the armoured face conveyors used in gate ends drifted in stone.

\subsection{Test rig}

A view and a diagram of the test rig used in the wear tests are shown in Fig. 1. A diagram of the load of the chain wheels for the abrasive wear test is shown in Fig. 2A, while for the abrasive-dynamic test - in Fig. 2B.

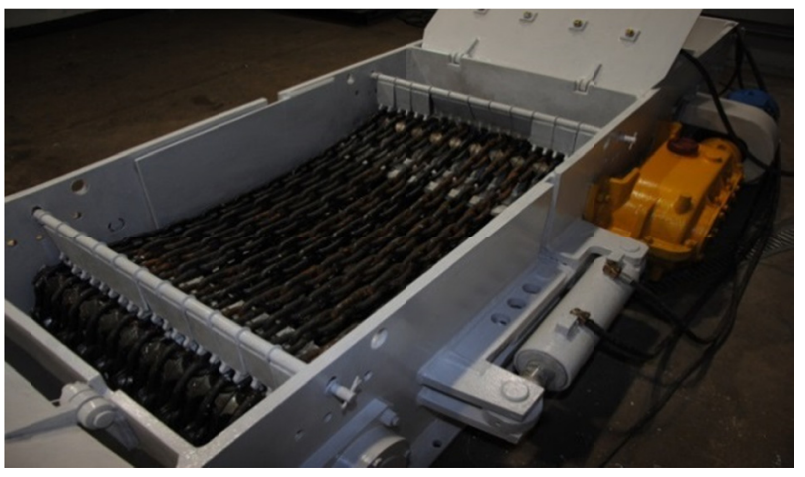

A

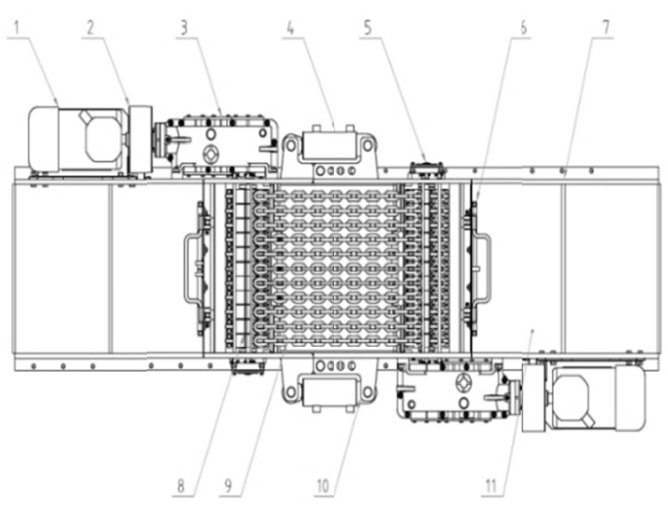

B

Fig. 1. Test rig, A. View B. Diagram; designations: 1 - Induction motor $22 \mathrm{~kW}, 2$ - Flexible coupling, 3 - Conical-cylindrical reduction gear, 4 - Hydraulic cylinder, 5 - Axle shaft, 6 - Sprinkler system for the test chamber, 7 - Body of the test rig, 8 - Test samples, 9 - Chain, 10 - Mounting bracket of the hydraulic cylinder, 11 - Additional chamber for aggregate

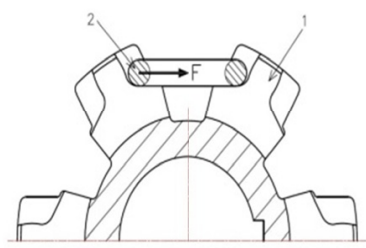

A

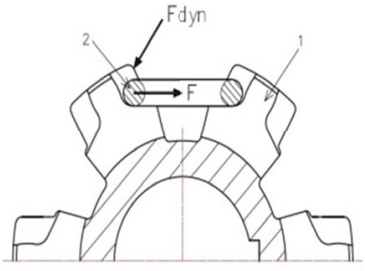

B
Fig. 2. Diagram of the load of a drum chain; A - for variant 1 of the wear test, B - diagram of the load of the chain drum for variant 1 of the wear test; designations: 1 - chain wheel, 2 - chain, $\mathrm{F}$ - driving force, Fdyn - external dynamic force obtained by the use of beaters

The design of the test rig enabled filling of the test box with any abrasive mixture as well as inducing an external force. Beaters with the mass of $1 \mathrm{~kg}$ were installed in the test rig in such a way that each tooth of the chain wheel was hit during the rotation of the drive shaft.

Fig. 3A presents a view of the test chamber of the test rig during the wear tests in the presence of quartz abrasive, while Fig. 3B shows a view of the chamber with installed beaters for the wear test with a dynamic load (abrasive-dynamic test).

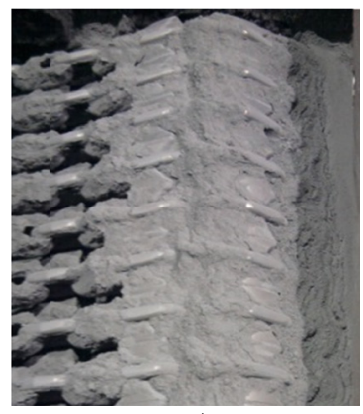

A

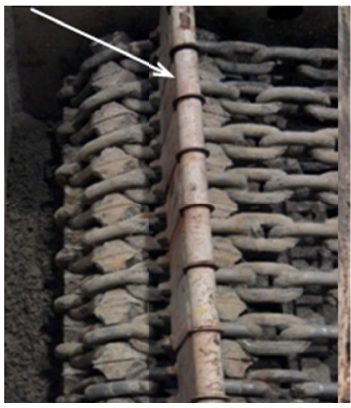

Fig. 3. Test rig, A - a view of the test chamber of the test rig during the wear tests with dry quartz abrasive (variant 1 ), $\mathrm{B}-\mathrm{a}$ view of the test chamber of the test rig during the wear tests with dry quartz abrasive and a dynamic load (variant 2); the arrow indicates the installed beaters

Table 1 presents the variants of combination of factors that induce destructive processes, which are used in the presented stage of the research process.

TABLE 1

Combination of variants and factors that induce destructive processes

\begin{tabular}{|c|c|c|}
\hline \hline $\begin{array}{c}\text { Variant } \\
\text { number }\end{array}$ & $\begin{array}{c}\text { Factors accelerating } \\
\text { destructive processes }\end{array}$ & $\begin{array}{c}\text { Simulated destructive } \\
\text { processes }\end{array}$ \\
\hline Variant 1 & Dry abrasive (quartz sand) & Abrasive wear \\
\hline Variant 2 & $\begin{array}{c}\text { Dry abrasive (quartz sand) } \\
\text { and an external dynamic load }\end{array}$ & $\begin{array}{c}\text { Abrasive wear and the } \\
\text { action of dynamic forces }\end{array}$ \\
\hline
\end{tabular}

\subsection{Characteristics of the object of tests}

The object of tests were chain wheels (Fig. 3) made of alloy cast steels: GS42CrMo-4, L35GSM, L30GS, 20HGSNM and A6. 


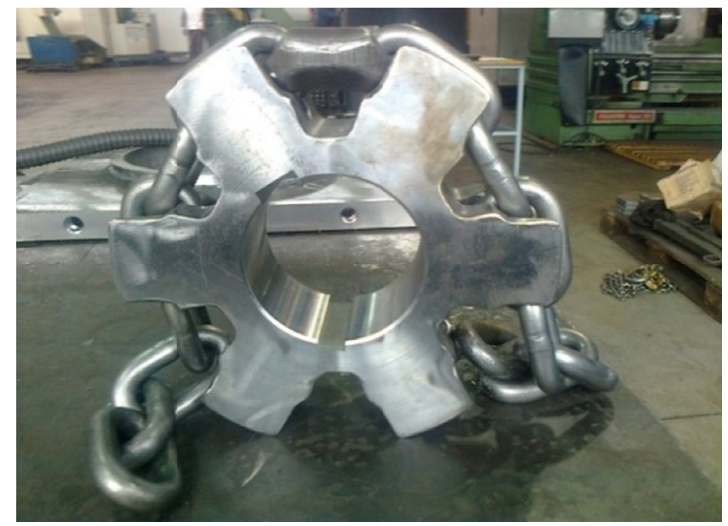

Fig. 4. Test chain wheels

The test chain wheels were cast in sand moulds and subjected to normalization as well as quenching and tempering. After the final machining, the chain wheels were subjected to surface hardening. The surface hardening was performed using the flame method; the surfaces subjected to machining were heated to a temperature of approx. $800^{\circ} \mathrm{C}$, and then cooled in $6 \%$ solution of water-polymer coolant.

Two identical sets of chain wheels were used for the wear tests. One of them was subjected to shot peening. The shotpeened chain wheels in the area of the contact between the wheel and the chain (Fig. 4) were subjected to a dynamic treatment with the Almen intensity of $0.32 \% \mathrm{mmA}$ and the coverage of $2 \times 100 \%$. Shot peening was conducted with the use of cut and rounded shot with the diameter of $0.6 \mathrm{~mm}$ and the hardness of approx. 54 HRC. Sample views of the surface subjected to shot peening, obtained on the basis of observations with the use of HITACHI S-3500N scanning electron microscope, are shown in Fig. 5. As a result of the action of shot on the tooth surface, there were formed flat deformations with distinct borders of the areas deformed (Fig. 6A) and cracks appeared in the surface layer (Fig. 6B).

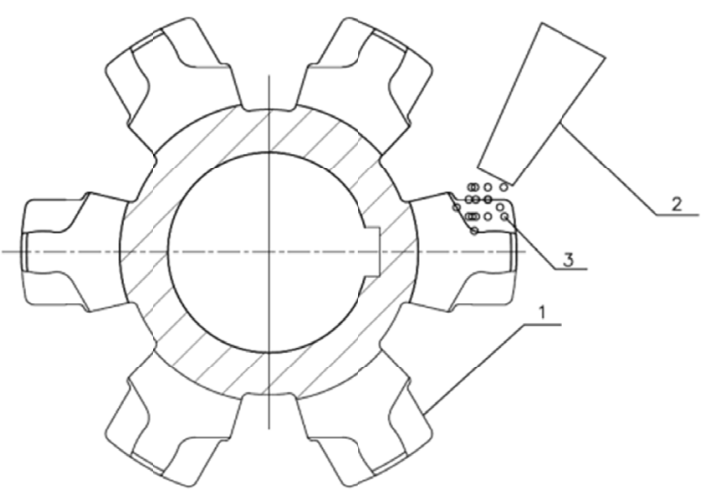

Fig. 5. Diagram of the process of shot peening of chain wheels; 1 - area of mating of the chain drum, 2 - nozzle of the shot-peening machine, $3-$ shot

The chemical composition of the cast steels subjected to the tests was compared in Table 2, while the mechanical properties are presented in Table 3.

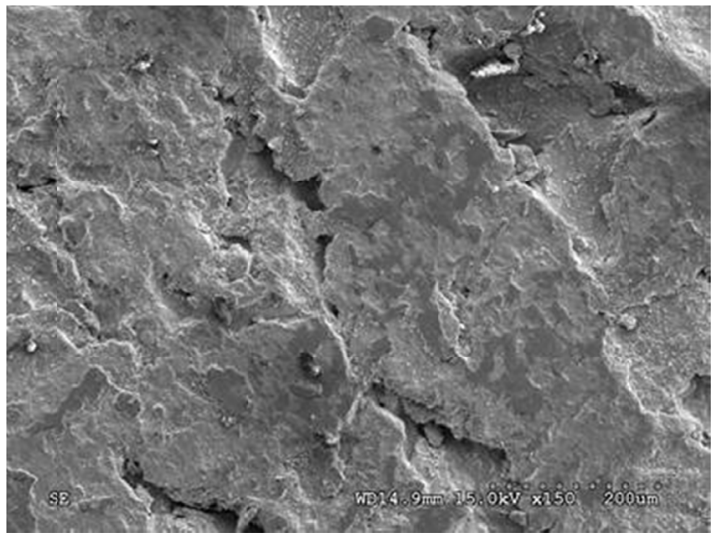

A

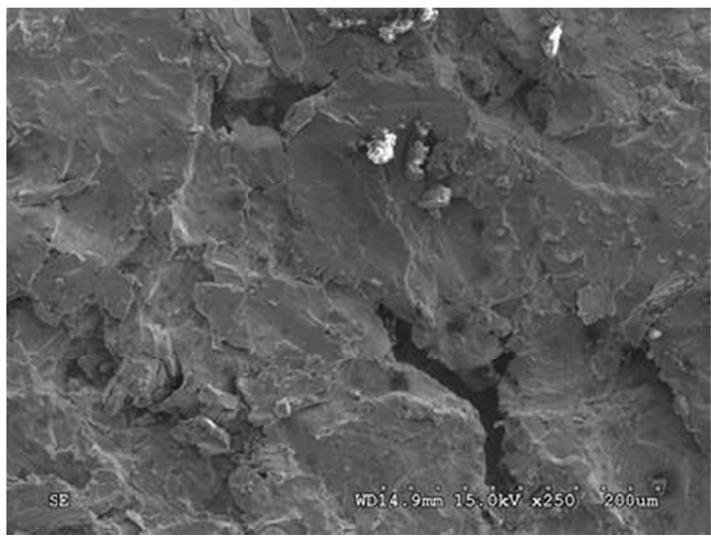

B

Fig. 6. Deformations of the surface of the chain wheels made of GS42CrMo4 cast steel caused by the action of shot; A - flat deformations with distinct borders of the areas deformed, B - cracks in the surface layer

TABLE 2

Chemical composition of cast steel [mass\%]

\begin{tabular}{|c|c|c|c|c|c|c|}
\hline \hline Designation & $\mathbf{C}$ & $\mathbf{S i}$ & $\mathbf{M n}$ & $\mathbf{C r}$ & $\mathbf{N i}$ & $\mathbf{M o}$ \\
\hline GS42CrMo4 & 0,35 & 0,38 & 0,72 & 1,21 & 0,06 & 0,5 \\
\hline L35GSM & 0,36 & 0,67 & 1,27 & - & - & 0,036 \\
\hline 20HGSNM & 0,22 & 0,82 & 0,91 & 0,78 & 0,95 & 0,16 \\
\hline L30GS & 0,28 & 0,636 & 1,27 & 0,096 & 0,106 & - \\
\hline A6 & 0,295 & 0,52 & 1,295 & - & - & - \\
\hline
\end{tabular}

\subsection{Test method}

The main wear tests were carried out in the presence of loose quartz abrasive for 200 hours, 100 hours for each direction of rotation of the motors. The tangential velocity of the chain wheels was $v=0.7 \mathrm{~m} / \mathrm{s}$, while the energy consumed by each of the motors was $\mathrm{PM}_{1}=\mathrm{PM}_{2}=7.5 \mathrm{~kW}$. The surface pressures between the surface of the wheel and the chain (determined using the finite element method) were at the level of $48.9 \mathrm{MPa}$, while the maximum equivalent stresses at the tooth base were at the level of $2.18 \mathrm{MPa}$.

Metallographic tests and measurements of hardness were carried out after the wear tests. Hardness was determined with the use of the Brinell HB method on hardened surfaces of the side teeth (Fig. 7). The structure was determined by cutting out 
Mechanical properties of the tested cast steels

\begin{tabular}{|c|c|c|c|}
\hline $\begin{array}{c}\text { Mechanical } \\
\text { Properties }\end{array}$ & $\begin{array}{c}\text { Tensile Strength } \\
\text { TS, MPa }\end{array}$ & $\begin{array}{c}\text { Yield Strength } \\
\text { YS, MPa }\end{array}$ & $\begin{array}{c}\text { Elongation } \\
\text { A5, \% }\end{array}$ \\
\hline GS42CrNiMo4 & $1115 \pm 3,8$ & $905 \pm 3,6$ & $8,9 \pm 0,1$ \\
\hline L20HGSNM & $1134 \pm 4,0$ & $1083 \pm 3,8$ & $10,0 \pm 0,1$ \\
\hline L30GS & $631,8 \pm 3,1$ & $396 \pm 3,0$ & $17,8 \pm 0,1$ \\
\hline A6 & $739 \pm 3,8$ & $526 \pm 3,4$ & $16,3 \pm 0,1$ \\
\hline L35GSM & $1152 \pm 3,7$ & $891 \pm 3,7$ & $8,7 \pm 0,1$ \\
\hline
\end{tabular}

samples from the area of mating between the chain wheel and the chain. Then the samples were ground, polished and etched with $2 \%$ Nital solution. The microscopic observations were performed using Zeiss AXIO Observer optical microscope.

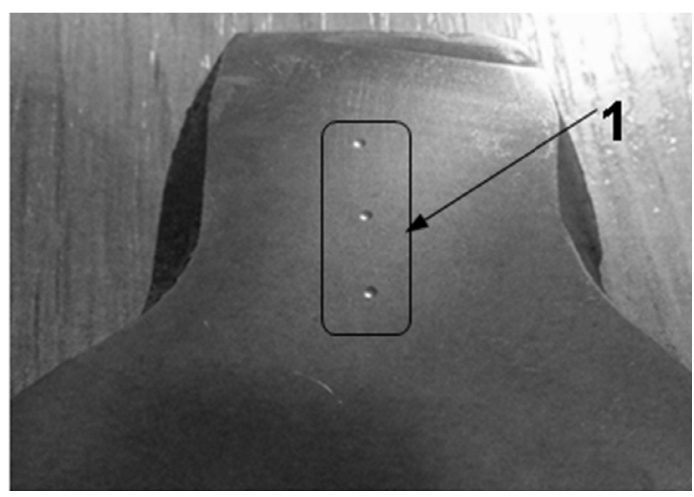

Fig. 7. A view of the area (1) of the tooth subjected to Brinell hardness test

In order to determine the abrasive wear of the chain wheels, the areas of mating between the chain wheel and the chain were measured before and after the wear test using a coordinate measuring machine (Fig. 8). The area of mating between the wheel and the chain was represented by at least 300 points making up the route of the measuring head of the machine (Fig. 9).

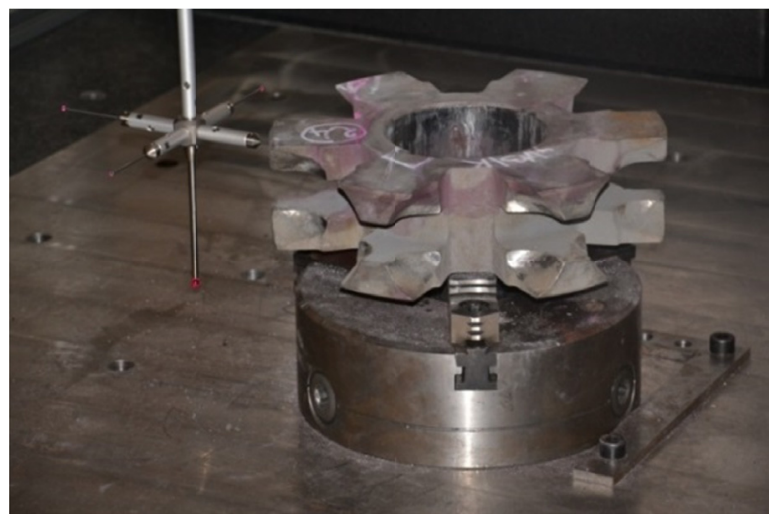

Fig. 8. A view of a chain wheel during the measurements on the coordinate measuring machine

Both groups of data obtained before and after the wear tests allowed determining the extent of the abrasive wear of individual

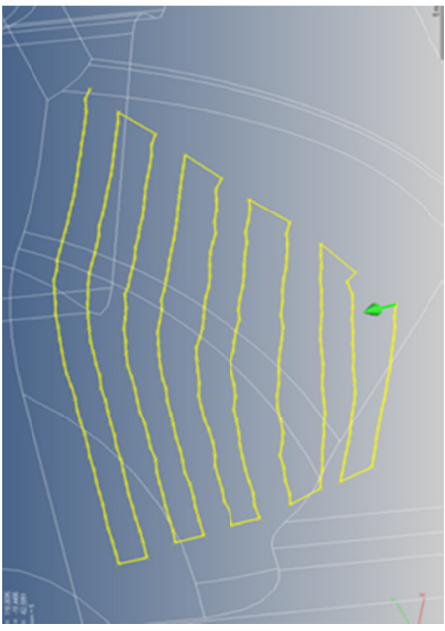

Fig. 9. A view of the route of the measuring head superimposed on the model of the chain wheel (the arrow indicates the end point of the route of the measuring head)

teeth of the chain drum. Fig. 10 shows the effect of merging the first 4 lines of the route of the measuring head determined before and after the wear tests. It can be easily seen that these paths merge, giving as a result a surface with a variable height, on the basis of which the measures characterising the abrasive wear of the chain wheels can be determined.

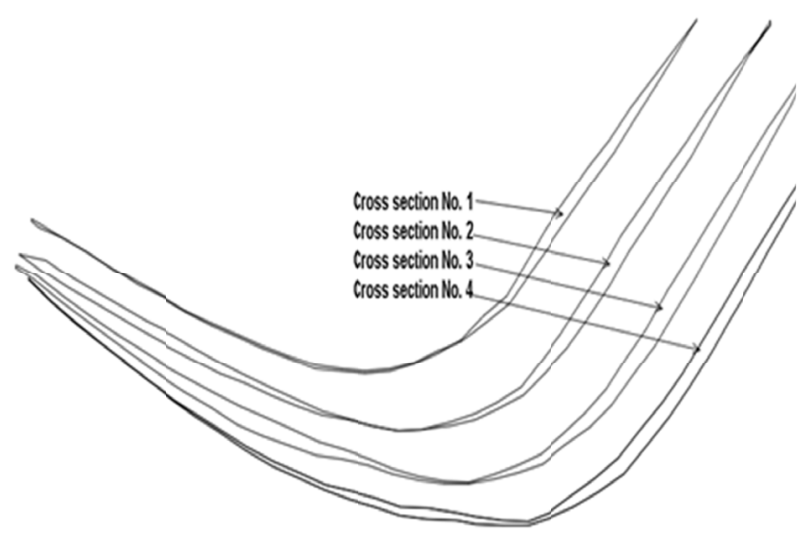

Fig. 10. A view of the surfaces obtained using the data from the measurement of the surface of a tooth made of GS42CrNiMo4 cast steel, before and after the wear test

In this study, the parameter $\delta_{i, N}$ was adopted as the main measure of wear. This parameter determines the measured difference (before and after the wear test) in the position of the $i$-th point of the route of the measuring head of the $N$-th tooth of the chain drum. The wear of a single measuring point $\delta_{i, N}$ is determined by the equation (3):

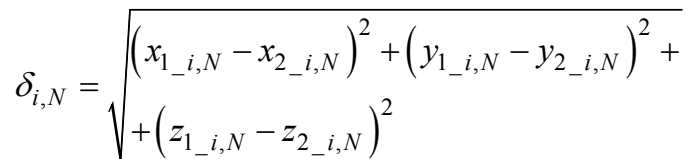

where:

$x_{1 \_i, N}-x$ coordinate of the $i$-th point of $N$-th teeth before the test, 
$x_{2} i, N-x$ coordinate of the $i$-th point of $N$-th teeth after the test,

$y_{1 \_i, N}-y$ coordinate of the $i$-th point of $N$-th teeth before the test,

$y_{2} i, N-y$ coordinate of the $i$-th point of $N$-th teeth after the test,

$z_{1 \_i, N}-z$ coordinate of the $i$-th point of $N$-th teeth before the test,

$z_{2} i, N-z$ coordinate of the $i$-th point of $N$-th teeth after the test,

$N$ - number of measured teeth.

On the basis of the value of wear of the $i$-th point of the measuring route $\delta_{i, N}$ determined for each $N$-th tooth, the values $\delta_{i_{-} A V G}$ averaged in relation to all the measures tooth surfaces of a given chain wheel were determined with the use of the following relationship:

$$
\delta_{i_{-} A V G}=\frac{\sum_{1}^{n} \delta_{i, N}}{n}
$$

where: $n$ - the number of seat surfaces of a given chain wheel $(n=24)$.

Using the determined values of the wear parameter $\delta_{i, N}$, a single-figure indicator of the maximum wear $\delta_{M A X}$ was determined using the following dependence:

$$
\delta_{\text {MAX }}=\frac{\sum_{1}^{n} \operatorname{Max}\left\{\delta_{i, N}\right\}}{n}
$$

The adopted indicator of the maximum wear $\delta_{M A X}$ was considered to be a parameter characteristic of the wear of surfaces mating during the process of operation of chain wheels. This assumption can be substantiated by the dependence of the hardness of the surface layer on the distance from the surface. The hardness of this layer varied significantly - from the surface, where it reached the highest values, to the core. Faster wear of the hardened layer leads to a situation where the abrasive cuts the unhardened material. The consequences include a substantial wear of the chain wheel surface which prevents the chain wheel from performing its driving function, a fracture of a tooth or a plastic deformation at the point of contact with the chain. The indicator of the maximum wear $\delta_{\text {MAX }}$ prefers the maximum values of wear measured along the route of the measuring head, and thus determines the total resistance of a given material to abrasive wear and to possible cracks in the surface layer. In order to determine the spread of the results in relation to the value $\delta_{M A X}$, standard deviations $s_{\delta}$ were also determined.

On the basis of the determined values of the averaged wear of the $\mathrm{i}$-th point of the measuring route $\delta_{i A V \mathrm{G}}$, there were determined the course of this parameter along the adopted route of the measurement as well as histograms of the wear values. The parameter $\delta_{i A V G}$ determines the depth of the surface layer material removed as a result of the action of the quartz abrasive. For the purpose of further analysis, it has been assumed that this parameter will be presented with the minus sign, which will facilitate the understanding of the physical meaning of the presented courses of the value $\delta_{i_{-} A V G}$.

\section{Results and discussion}

The basic mechanism of destruction of the wheel surfaces mating with the link chain in the presence of quartz abrasive was the process of microcutting. The effects of the cutting action of quartz grains are illustrated in Fig. 11. Large cuts caused by the action of the abrasive can be easily seen in the material of the chain wheel.

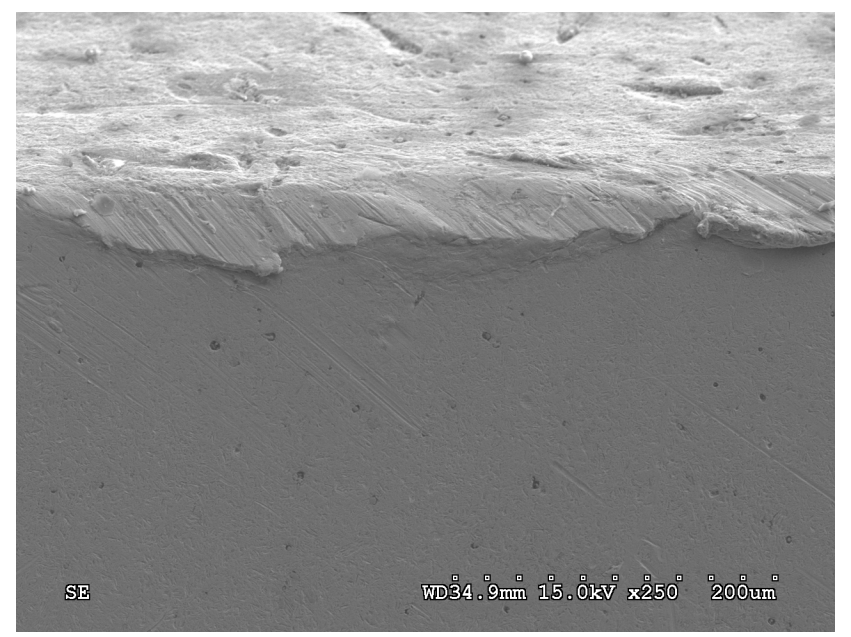

Fig. 11. Traces of microcutting by grains of quartz abrasive on the surface of a wheel made of L35GSM steel

When observing the form of damage in the area of mating between the chain and the chain wheel, the following types of abrasion can be noticed:

- flat abrasions in the area of mating with distinct border between the zone subjected to the wear and the zone not subjected to the wear (Fig. 12A); small single cavities may occur in the area of abrasion (Fig. 12B),

- deep abrasions in the area of mating having a lenticular shape (Fig. 12C and 12D),

- $\quad$ abrasions in the area of mating with noticeable fairly deep cracks (Fig. 12E and 12F).

After the metallographic examinations had been carried out, it has been found for the analysed L20HGSNM, GS42CrMo4, A6, L30GS and L35GSM cast steels that in their surface layer there occurred tempered martensite formed as a result of the surface hardening process. In the core of the chain wheels, there was found fine-grained sorbite formed as a result of normalization as well as quenching and tempering of the casts. Non-metallic inclusions were observed in the structure of the casts (sample views of the inclusions are shown in Fig. 14). They were located mainly in the areas of contact between the sand mould and the molten metal.

The determined values of wear $\delta_{M A X}$ for two variants of surface treatment and two variants of combination of operating factors along with the standard deviation are shown in Table 4. The same table shows the measured average values of the hardness $H B_{A V G}$ of the chain wheels tested for the materials considered. 


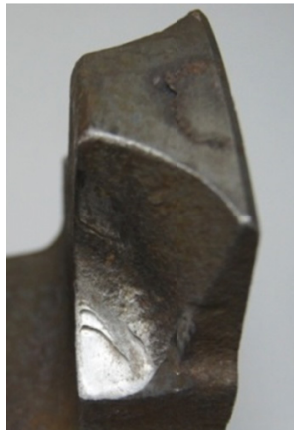

A

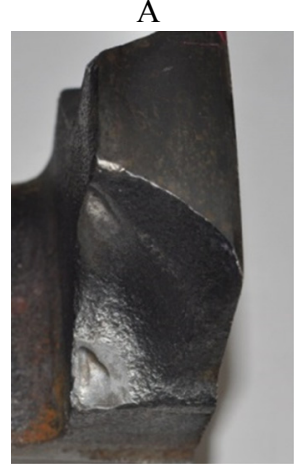

C

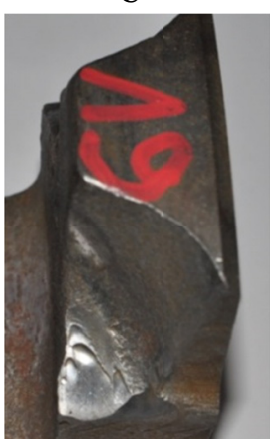

$\mathbf{E}$

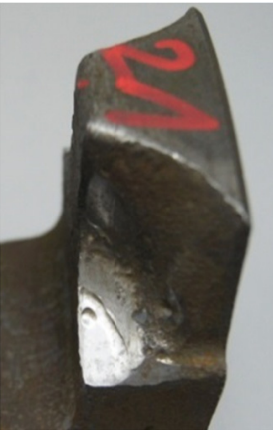

B

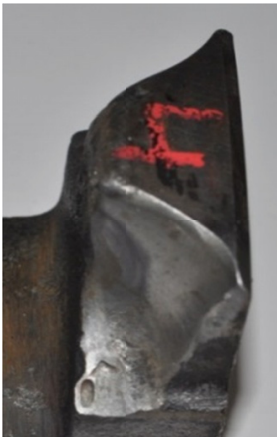

D

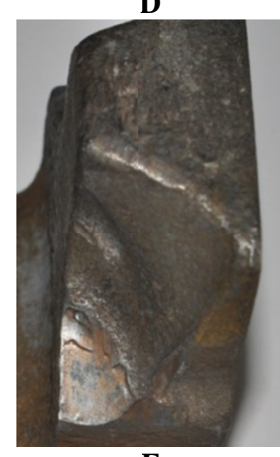

$\mathbf{F}$
Fig. 12. A view of the area of mating between the cast steel wheels and the chain; A - L35GSM, B - L20HGSNMA, C - GS42CrMo4, D - L30GS, E - GS42CrMo4_SP, F - A6

Fig. 15 shows examples of graphs of the value of averaged wear of the $i$-th point of the measuring route $\delta_{i A V G}$ for the shotpeened and not shot-peened variants of the chain wheel made of the $35 \mathrm{GSM}$ cast steel, while Fig. 15 presents histograms of this parameter. Based on Table 4, Fig. 14 and Fig. 15, an increase in the wear of the chain wheels subjected earlier to shot peening can easily be noticed. The increased wear may result from deformations and cracks of the surface caused by the dynamic action of the shot (Fig. 5), which facilitate cutting of the material by the grains of quartz sand.

The impact of the additional dynamic force on the wear is relatively low (Tab. 4) for the wheels made of the L35GSM, L20HGSNM and GS42CrMo cast steels not subjected to shot peening as well as for the wheels made of the L35GSM and L20HGSNM cast steels subjected to shot peening which are characterized by hardness $H B \geq 500$. This is also confirmed by the courses of the wear parameter $\delta_{i \_A V G}$ determined for the L35GSM cast steel, which are shown in Fig. 17, as well as the values of the abrasive wear $\delta_{M A X}$ of the chain wheels not sub-

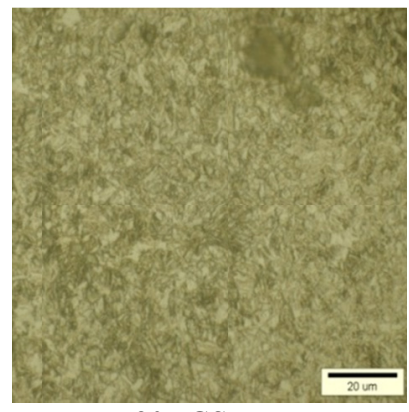

L20HGSNM

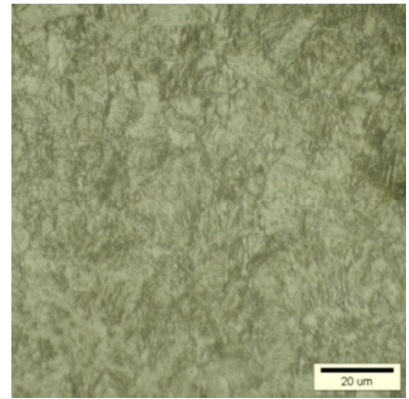

L30GS

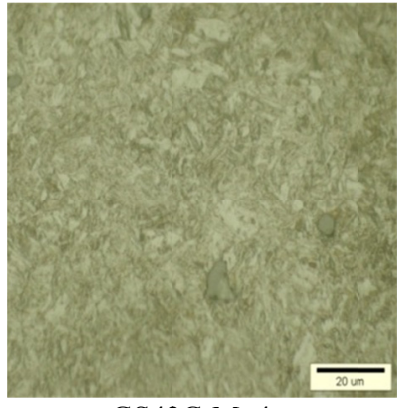

GS42CrMo4

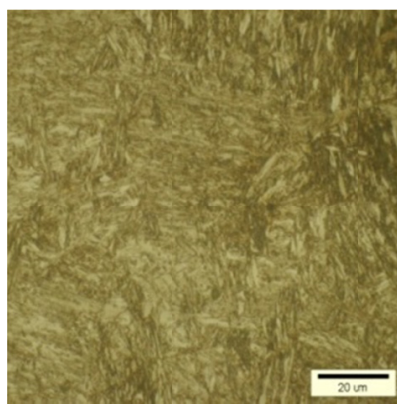

A6

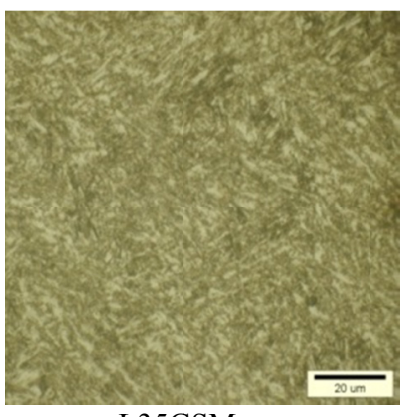

L35GSM

Fig. 13. The microstructure $2 \mathrm{~mm}$ under the surface of the tested cast steels

TABLE 4

The wear $\delta_{M A X}$ and average hardness HBAVG for examined materials

\begin{tabular}{|c|c|c|c|}
\hline Designation & $\delta_{M A X}, \mathbf{m m}$ & $S_{\delta}, \mathbf{m m}$ & $H B_{A V G}$ \\
\hline A6 & 1,456 & 0,194 & \multirow{4}{*}{$450 \pm 9$} \\
\hline A6_SP & 1,694 & 0,258 & \\
\hline A6_D & 1,785 & 0,033 & \\
\hline A6_SPD & 2,584 & 0,044 & \\
\hline L30GS & 1,601 & 0,283 & \multirow{4}{*}{$468 \pm 8$} \\
\hline L30GS_SP & 1,652 & 0,183 & \\
\hline L30GS_D & 1,986 & 0,089 & \\
\hline L30GS_SPD & 2,116 & 0,034 & \\
\hline L35GSM & 0,890 & 0,199 & \multirow{4}{*}{$500 \pm 8$} \\
\hline L35GSM_SP & 1,330 & 0,326 & \\
\hline L35GSM_D & 0,939 & 0,053 & \\
\hline L35GSM_SPD & 1,351 & 0,035 & \\
\hline L20HGSNM & 0,809 & 0,164 & \multirow{4}{*}{$514 \pm 9$} \\
\hline L20HGSNM_SP & 1,308 & 0,369 & \\
\hline L20HGSNM_D & 0,915 & 0,067 & \\
\hline L20HGSNM_SPD & 1,378 & 0,069 & \\
\hline GS42CrMo4 & 0,950 & 0,226 & \multirow{4}{*}{$551 \pm 7$} \\
\hline GS42CrMo4_SP & 1,182 & 0,288 & \\
\hline GS42CrMo4_D & 1,042 & 0,118 & \\
\hline GS42CrMo4_SPD & 1,545 & 0,040 & \\
\hline
\end{tabular}



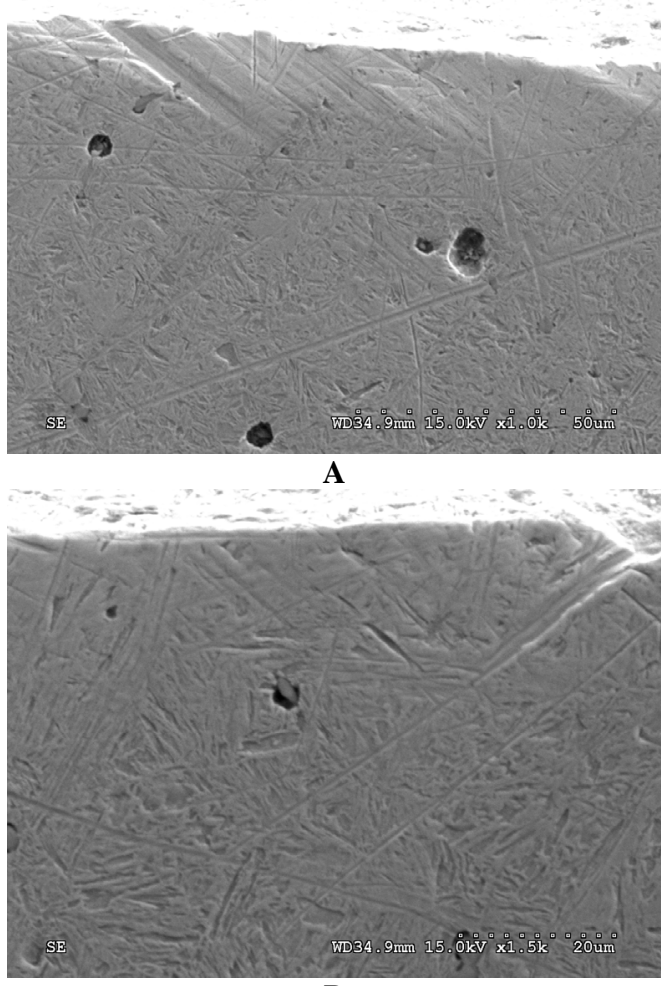

B

Fig. 14. Examples of non-metallic inclusions in the microstructure of the L35GSM cast steel

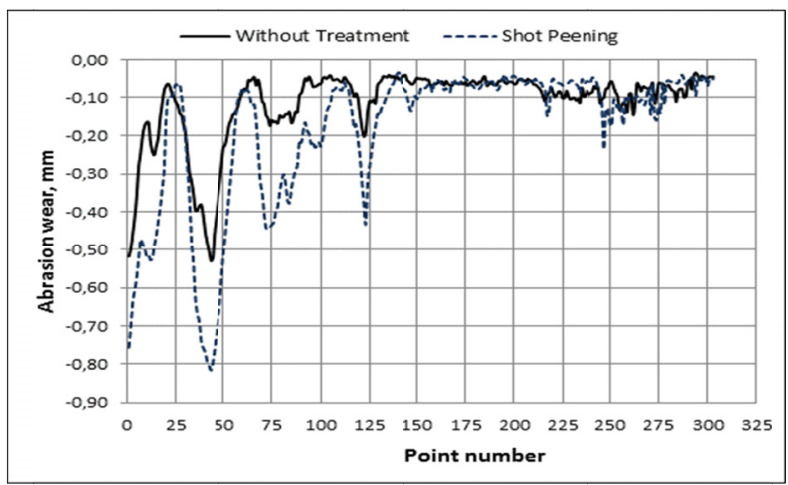

Fig. 15. Graphs of the value of averaged wear of the $i$-th point of the measuring route $\delta_{i A V G}$ determined for the shot-peened and not shotpeened variants of the chain wheel made of the L35GSM cast steel

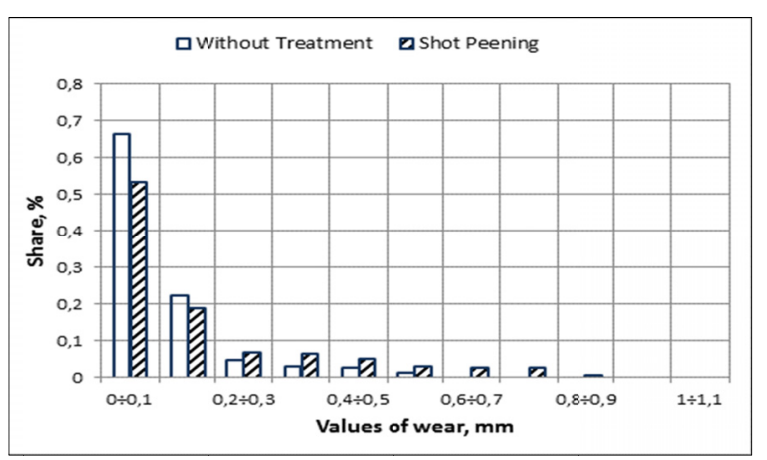

Fig. 16. Histograms of the value of averaged wear of the $i$-th point of the measuring route $\delta_{i A V G}$ determined for the shot-peened and not shot-peened variants of the chain wheel made of the $35 \mathrm{GSM}$ cast steel jected to shot peening as a function of the average hardness of the surface, which are presented on Fig. 18A.

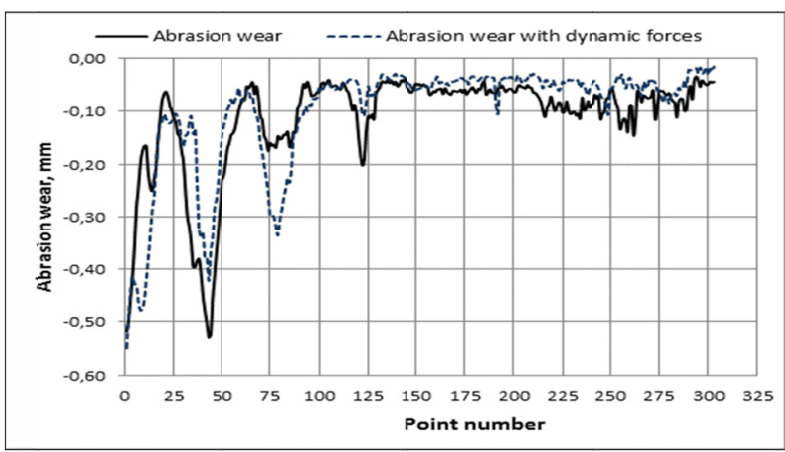

A

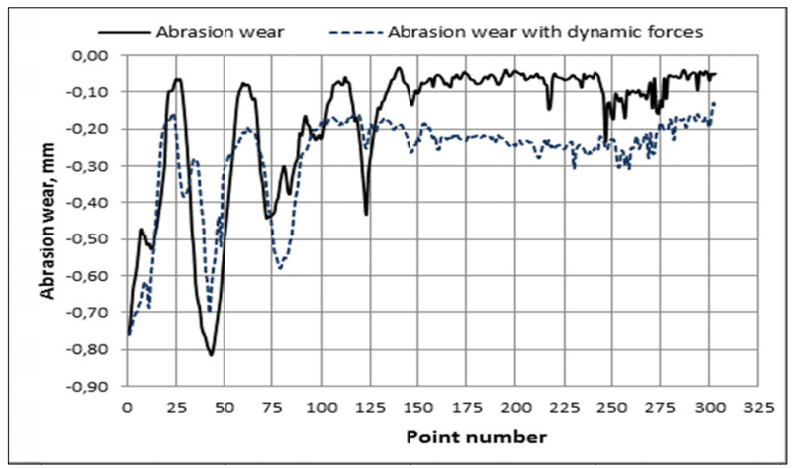

B

Fig. 17. Graphs of the value of averaged wear of the $i$-th point of the measuring route $\delta_{i A V G}$ determined for the chain wheel made of the L35GSM cast steel, A - wheels not subjected to shot peening, B - wheels subjected to shot peening
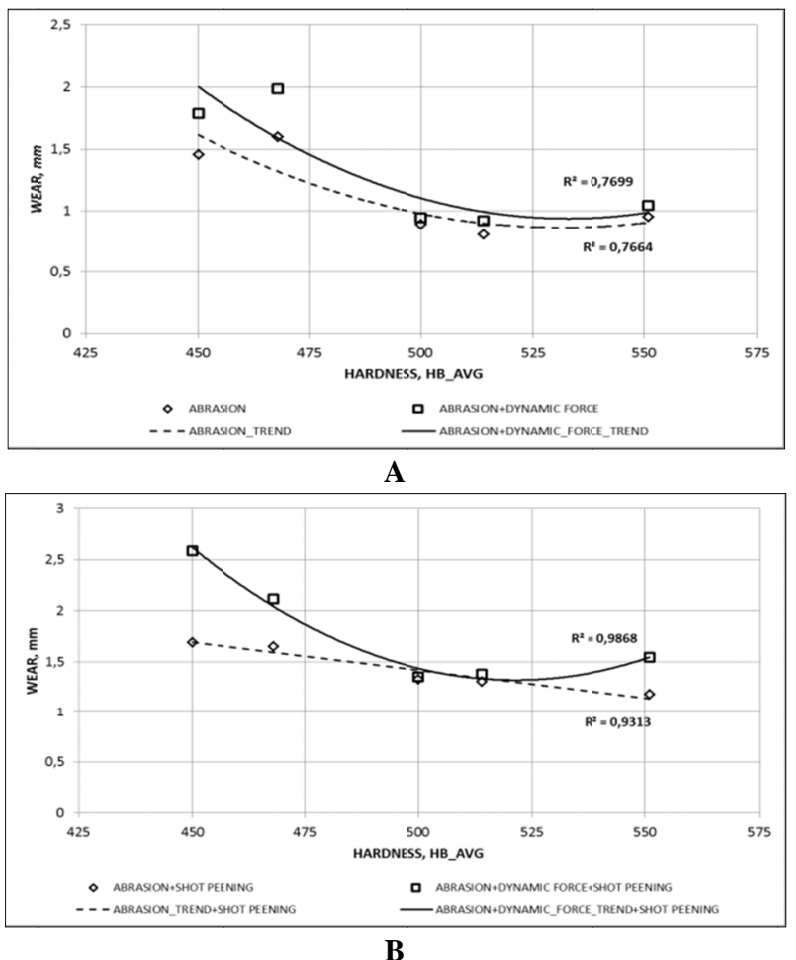

Fig. 18. The impact of an additional dynamic force on the abrasive wear the chain wheels tested as a function of the average surface hardness $H B_{A V G}, \mathrm{~A}$ - wheels not subjected to shot peening, $\mathrm{B}$ - wheels subjected to shot peening 
An additional dynamic force has a significant impact on the abrasive wear in the case of the A6 and L30GS manganese cast steels. When analysing Fig. 18, there can be noticed a differentiation in the values of the abrasive wear as a function of the average surface hardness depending on the fact whether the wheels were subjected to shot peening or not.

For the non-shot peened variant, the graphs of the wear of the chain wheels, both in the case of their operation with an additional dynamic force and without it (Fig. 18A) have the same non-linear character. The chain wheels operated without the presence of a dynamic force were characterized by greater resistance to wear. Assuming the synergistic component $\Delta V_{D Y N}$, determined from the equation (2), as a measure of the impact of the dynamic force on the wear, in percentage terms this component ranged from 10 to $25 \%$ (Fig. 19).

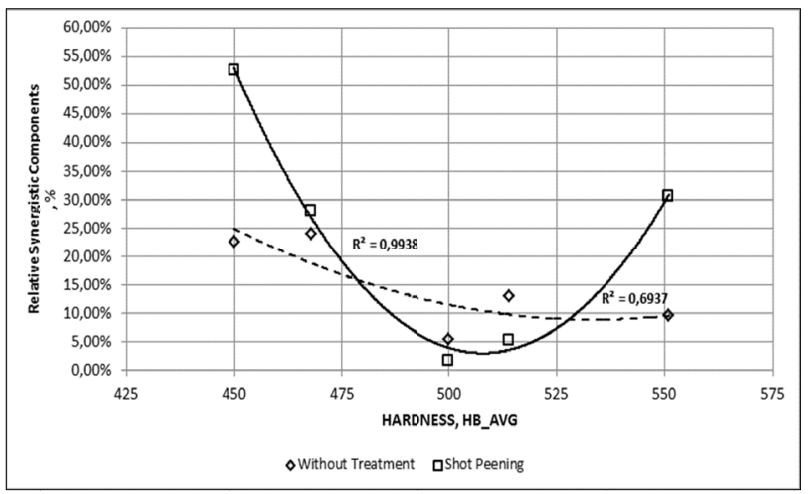

Fig. 19. The values of the synergistic component $\Delta V_{D Y N}$ as a function of the average surface hardness of the materials tested

The graphs of the wear of shot-peened chain wheels as a function of the average surface hardness of the materials tested differ significantly from each other in the cases of the operation with an additional dynamic force and without it (Fig. 18B). The graph obtained in the conditions of the destructive action in presence of the abrasive only is linear, while the graph for the case of the combined action of the abrasive and a dynamic force has a parabolic shape with a distinct minimum at the hardness of $500 \mathrm{HB}$. The differentiation in the value of the synergistic component $\Delta V_{D Y N}$ is significantly higher in comparison with the wheels not subjected to shot peening, as it ranges from 2 to $52 \%$ (Fig. 19).

In the case of the GS42CrMo4 cast steel subjected to shot peening, the impact of the dynamic force resulted in greater increases in the wear as compared with cast steels of similar hardness, such as L35GSM and L20HGSNMA. Fig. 20 shows a comparison of the values of the averaged wear $\delta_{i_{-} A V G}$ obtained at the presence of a dynamic force and without it for both surface preparation variants of the GS42CrMo4 cast steel. The presence of the dynamic force for both variants of chain wheels resulted in an increased wear, but for the shot-peened variant this increase was significantly greater (Fig. 20B).

When analysing the microstructure of the surface layer of the GS42CrMo4 cast steel operated in the presence of the abrasive only (Fig. 21), many oblique microcuts were observed.

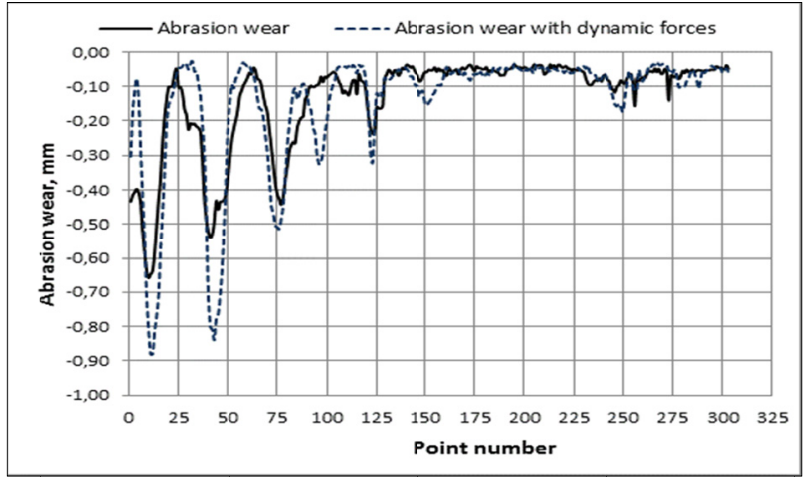

A

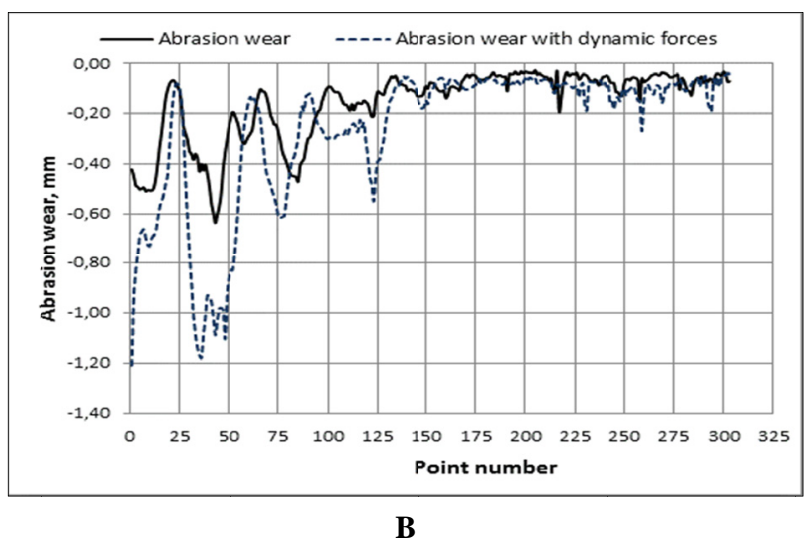

Fig. 20. Graphs of the value of averaged wear of the $i$-th point of the measuring route $\delta_{i A V G}$ determined for the chain wheel made of the GS42CrMo-4 cast steel, A - wheels not subjected to shot peening, $\mathrm{B}$ - wheels subjected to shot peening

Cracks were propagated from their vertexes down into the surface layer and in many cases they reached the place where non-metallic inclusions were located. It can be supposed that the resulting cavity with an additional crack is conducive to further cracking of this fragment and enlarging of the damage to the surface. The case shown in Fig. 21 is typical of the materials susceptible to brittle cracking [13].

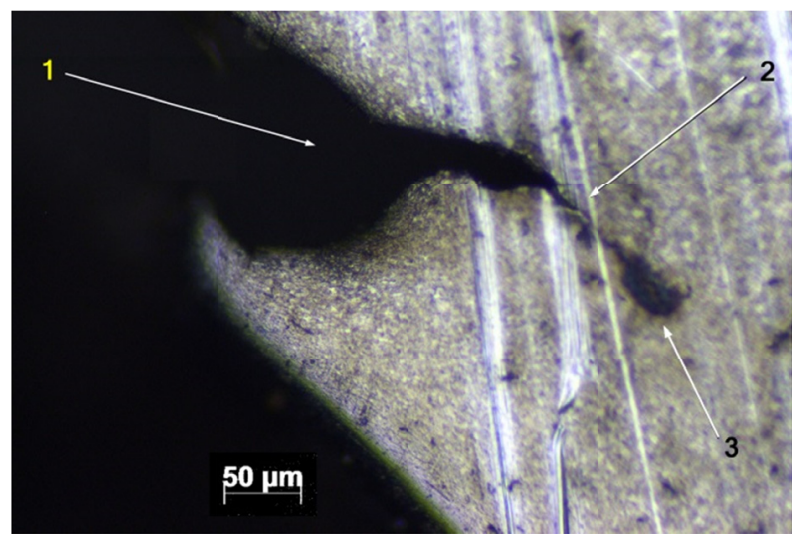

Fig. 21. Microstructure of the GS42CrMo4 cast steel; 1 - microcut, 2 - crack, 3 - non-metallic inclusions

It has been demonstrated in [14] that for the $42 \mathrm{CrMo} 4$ steel (chemical composition of this steel was similar to the composi- 
tion of the cast steel subjected to the tests) the values of the $\mathrm{KC}$ parameter were differentiated depending on the variation in the phase composition of the microstructure; it has been found that the martensite structure is more susceptible to cracking. It should be reminded that the GS42CrMo4 cast steel was characterized by the highest surface hardness of all the examined cast steels, which may suggest its highest susceptibility to cracking in the hardened layer among all the materials tested. The observed increase in the abrasive wear of the GS42CrMo4 cast steel was probably associated with a deeper propagation of cracks into the surface layer (see Fig. 21) in the presence of an additional dynamic force. The shot peening of casts performed earlier results in the occurrence of cracks on the surface (Fig. 6B) which facilitate the penetration and cutting of the surface by abrasive grains. They are also places with stress concentrations conducive to the formation of cracks in the surface layer.

\section{Conclusions}

1. The impact of the additional dynamic force accompanying the operation of chain wheels in the presence of quartz abrasive has a synergistic effect on the abrasive wear of these wheels.

2. The value of the abrasive wear of chain wheels operated in the conditions of the combined action of the abrasive and a dynamic force depends on whether the surface of the area of mating between the wheels and the chain was subjected to shot peening or not before the wear test.

3. An increase in the abrasive wear was observed for the wheels made of cast steel subjected to shot peening in the area of mating with the chain, regardless of whether the test was conducted in the presence of an additional dynamic force or without it.

4. The synergistic component $\Delta \mathrm{V}_{\mathrm{DYN}}$ examined in the percentage terms ranged from 10 to $25 \%$ for the chain wheels not subjected to shot peening and from 2 to $52 \%$ for the shot-peened wheels.

5. The L35GSM and L20HGSNMA cast steels with a surface hardness of approx. $500 \mathrm{HB}$ were characterised by the smallest increase in the synergistic component.

6. The formation of cracks in the surface layer, typical of brittle materials, affects the course of the process of wear of chain wheels made of the GS42CrMo4 cast steel.

\section{Acknowledgements}

The study was carried out as a part of the project "Innovative technology for production of tension members for transport systems with the use of cast materials", No. POIG.01.04.00-24-100/11.

\section{REFERENCES}

[1] R. Burdzik, P. Folęga, B. Łazarz, Z. Stanik, J. Warczek, Archives of Metallurgy and Materials 57 (4), 987-993 (2012).

[2] T. Burakowski, Reflections on the synergy in Surface Engineering (Rozważania o Synergizmie w inżynierii powierzchni). Wydawnictwo Politechniki Radomskiej, Radom 2004.

[3] A.N. Wieczorek, Archives of Metallurgy and Materials 59 (4), 1675-1683 (2014).

[4] D.P. Townsend, E.V. Zaretsky, Effect of shot peening on surface fatigue life of carburized and hardened AISI 9310 spur gears, NASA Technical Paper 2047, 5-12 (1982).

[5] D.P Townsend, Improvement in surface fatigue life of hardened gears by high-intensity shot peening, NASA Tech Report 91-C0421992.

[6] D. Kirk, Residual stresses and retained austenite in shot peened steels in ICSP-1, Paris, France 1981, 271-278.

[7] J. Champaigne, Shot peening overview, Metal Improvement Company 2001.

[8] M. Kobayashi, K. Hasegawa, Effect of shot peening on the pitting fatigue strength of carburised gears, in ICSP-4, Tokyo, 465-476, Japan 1990.

[9] A. Yoshida, Y. Ohue, M. Seki, Influence of shot peening on surface durability of plasma case-hardened sintered powder metal gears. Proceedings of DETC'03, Design Engineering Technical Conferences and Computers and Information in Engineering Conference Chicago, 1-8 2003.

[10] A.N. Wieczorek, Key Engineering Materials 674, 201-206 (2016).

[11] A.N. Wieczorek, Archives of Metallurgy and Materials 59 (4), 1665-1674 (2014).

[12] A.N. Wieczorek, W. Polis, Management Systems in Production Engineering 3 (19), 175-178 (2015).

[13] M. Srinivasan, Science and Technology of Casting Processes, Chapter 10 Fracture Toughness of Metal Castings (Authors of Chapter: M. Srinivasan, S. Seetharamu) (Doi: 10.5772/50297), 2012.

[14] P. Göncz, N. Gubeljak, R. Potočnik, S. Glodež, Advanced Engineering 4 (1), 2010. 